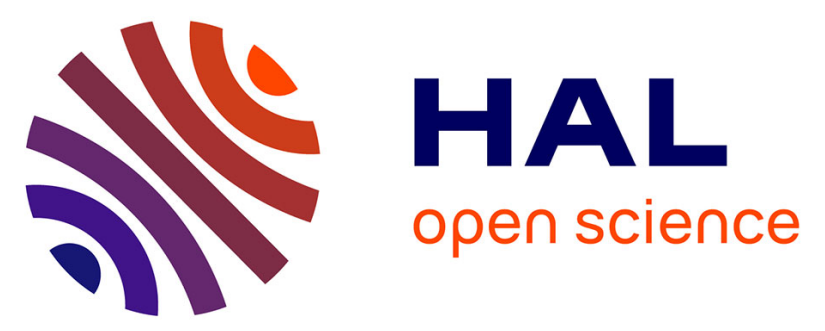

\title{
Bleaching Earths as Powerful Additives for Ru-Catalyzed Self-Metathesis of Non-Refined Methyl Oleate at Pilot Scale
}

Jessica Allard, Idriss Curbet, Guillaume Chollet, Fabien Tripoteau, Sophie Sambou, Frédéric Caijo, Yann Raoul, Christophe Crevisy, Olivier Baslé, Marc Mauduit

\section{To cite this version:}

Jessica Allard, Idriss Curbet, Guillaume Chollet, Fabien Tripoteau, Sophie Sambou, et al.. Bleaching Earths as Powerful Additives for Ru-Catalyzed Self-Metathesis of Non-Refined Methyl Oleate at Pilot Scale. Chemistry - A European Journal, 2017, 23 (52), pp.12729-12734. 10.1002/chem.201703049 . hal-01614771

HAL Id: hal-01614771

https://hal-univ-rennes1.archives-ouvertes.fr/hal-01614771

Submitted on 26 Oct 2017

HAL is a multi-disciplinary open access archive for the deposit and dissemination of scientific research documents, whether they are published or not. The documents may come from teaching and research institutions in France or abroad, or from public or private research centers.
L'archive ouverte pluridisciplinaire HAL, est destinée au dépôt et à la diffusion de documents scientifiques de niveau recherche, publiés ou non, émanant des établissements d'enseignement et de recherche français ou étrangers, des laboratoires publics ou privés. 


\title{
Bleaching Earths as Powerful Additives for Ru-Catalyzed Self- Metathesis of Non-Refined Methyl Oleate at Pilot Scale.
}

\author{
Jessica Allard, ${ }^{[a, b]}$ Idriss Curbet, ${ }^{[\mathrm{a}]}$ Guillaume Chollet, ${ }^{[\mathrm{c}]}$ Fabien Tripoteau, ${ }^{[\mathrm{d}]}$ Sophie Sambou, ${ }^{[\mathrm{b}]}$ Frédéric \\ Caijo, ${ }^{[\mathrm{d}]}$ Yann Raoul ${ }^{[\mathrm{b}]}$ Christophe Crévisy, ${ }^{[\mathrm{a}]}$ Olivier Baslé ${ }^{[\mathrm{a}]}$ and Marc Mauduit ${ }^{[\mathrm{a}]}$ *
}

Dedicated to

\begin{abstract}
A practical and cost-effective ruthenium-catalyzed selfmetathesis of non-refined methyl oleate (85\%) derived from Very High Oleic Sunflower Oils (VHOSO) was demonstrated at pilot scale using a robust and $\mathrm{kg}$-scale commercially available SIPr-M71 precatalyst. The simple addition of $1 \mathrm{wt} \%$ bleaching earths (Tonsil $110 F F)$ to a thermally pretreated oil could efficiently prevent catalyst deactivation. Remarkably, without the need for filtration, the catalytic system was able to achieve a turnover number of more than 744000 at a catalyst loading of only $1 \mathrm{ppm}$. At large scale (up to $200 \mathrm{Kg}$ ), the equilibrium of the self-metathesis reaction was reached within 1 hour at $50{ }^{\circ} \mathrm{C}$ under neat conditions at a very low $5 \mathrm{ppm}$ catalyst loading to produce the expected primary metathesis products (PMP), i.e. the 9-octadecene and the dimethyl-9-octadecenoate with a productive TON of 94900 .
\end{abstract}

Considering the ineluctable rarefaction of fossil resources, the catalytic transformation of biomass derivatives into valuable fine chemicals constitutes a promising alternative, which could be in high demands in the near future. ${ }^{[1]}$ Among the available renewable resources, natural oils have both the advantage of containing various reactive organic functions (e.g. alkenes, alcohols, acids, esters) and to be currently produced at multimillion tons/year. ${ }^{[2]}$ The self-olefin metathesis $(\mathrm{SM})^{[3]}$ of unsaturated fatty acids/esters from vegetable oils represents one of the most eco-efficient transformations with a remarkable low carbon footprint. ${ }^{[4]}$ For instance, the Ru-catalyzed SM of methyl oleate $(\mathrm{MO})(Z)-\mathbf{1}$, derived from various oils (e.g. soybean, canola or sunflower), produces two highly desirable molecules (9-octadecene (E/Z)-2 and dimethyl-9-octadecenoate $(E / Z)-3)$ as primary metathesis products (Scheme 1). ${ }^{[4]}$ The former can be readily converted into bio-sourced lubricants, surfactants or plasticizers, ${ }^{[5]}$ while the latter is considered as a precursor of monomers for the production of bio-sourced materials. ${ }^{[6]}$ In the last two decades, significant breakthroughs have been accomplished in metathesis of oleochemicals either

[a] Dr. J. Allard, I. Curbet, Dr. C. Crévisy, Dr. O. Baslé, Dr. M. Mauduit Ecole Nationale Supérieure de Chimie de Rennes, UMR CNRS 6226, 11 Allée de Beaulieu, CS 50837, 35708 Rennes Cedex 7, France

E-mail: marc.mauduit@ensc-rennes.fr

[b] Dr. J. Allard, Dr. S. Sambou, Dr. Y. Raoul

OLEON SAS, Venette BP 20609, 60206 Compiègne Cedex, France

[c] Dr. G. Chollet

ITERG, 11 rue Monge - Parc industrie Bersol 2, 33600 Pessac, France

[d] Dr. F. Tripoteau, Dr. F. Caijo

DEMETA SAS, 6 rue Pierre-Joseph Colin, 35000 Rennes, France

Supporting information for this article is given via a link at the end of the document.

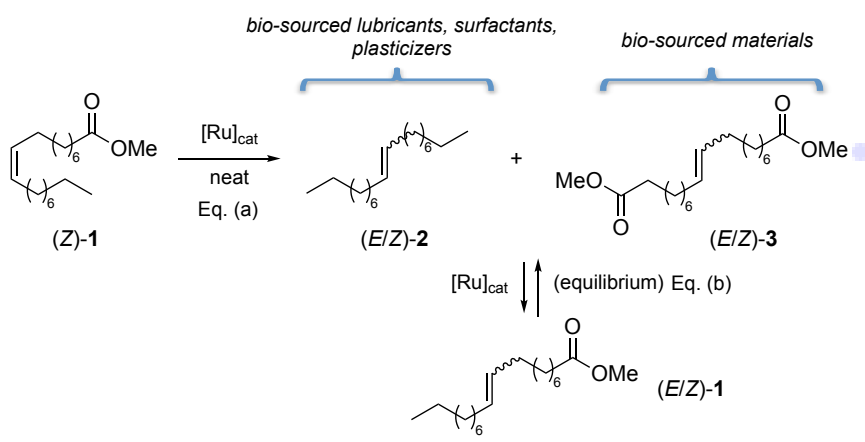

Scheme 1. Ru-catalyzed Self-metathesis of unsaturated fatty ester methyl oleate $(Z)-1$ derived from vegetable oils.

by academics or industrial companies, thanks to the development of robust and $\mathrm{kg}$-scale commercially available Rubased catalysts (Figure 2). For instance, Ru-2b was able to catalyze the SM of 1 at loadings as low as 1 ppm affording PMP 2 and 3 in $45 \%$ conversion at the equilibrium (Eq. b. Scheme 1) with the highest turnover number (TON) of 440000 reported so far. $^{[7]}$ The thienylmethylidene catalyst Ru-4 demonstrated also an impressive reactivity towards $\mathrm{MO}$ reaching a TON of 250 $000 .^{[8]}$ Nevertheless, the economical viability of industrial processes at multi-ton scale depends not only on the catalyst efficiency and selectivity, ${ }^{[9]}$ but also on the quality of the involved raw materials. ${ }^{[2 b]}$ In fact, such remarkable catalytic metathesis activities could not be reached without requiring prior alumina filtration of a costly high-purity grade of $\mathrm{MO}(>99 \%)^{[10]}$, that is incompatible with an industrial process.

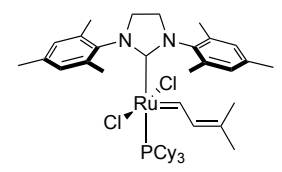

Ru-1 (Grubbs vinylidene)

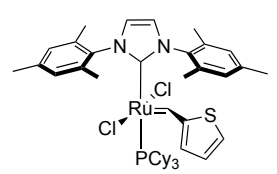

Ru-4 (Evonik RF2)

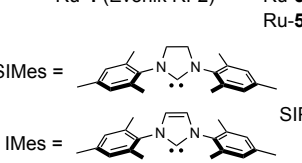

Figure 1. Benchmark of kg-scale commercially available Ru-1-6 pre-catalysts commonly used in metathesis of oleochemicals. 
Because the pre-treatment of the oleo-raw materials represents a key success factor for a cost-effective metathesis process, many efforts have been made to address this concern. ${ }^{[11]}$ Several methodologies to trap catalyst poisoning species present in vegetable oils (e.g. peroxides, phosphates, sulfates, soap...) were reported with varying degrees of success. The use of reductive reagents, inorganic bases or metallic alcoholates followed by successive aqueous washes and then filtration through a sorbent such as activated charcoal, alumina, magnesium silicate or celite proved to be efficient. ${ }^{[12]}$ The thermal pre-treatment $\left(100{ }^{\circ} \mathrm{C}\right)$ of methyl fatty esters under vacuum in combination with small amounts of a mix of sorbents (magnesium silicate/celite) represents the most effective process to date, allowing after filtration, the metathesis reaction with less than $10 \mathrm{ppm}$ of catalyst loadings (with Ru-1). ${ }^{[12 \mathrm{~d}]}$ However, due to a noticeable loss of the raw material during the filtration (up to $20 \mathrm{wt} . \%$ ), all these pretreatments would have significant impact on the total cost of production. Therefore, the development of a simple, ton-scalable, and cost-effective olefin metathesis process for the conversion of renewable fatty esters is still in high demands. Herein, we report an efficient rutheniumcatalyzed self-metathesis process to convert non-refined MO 1 (85\%) derived from Very High Oleic Sunflower Oils (VHOSO) into corresponding PMP 2 and $\mathbf{3}$ at pilot scale using a robust commercially available M71 complex Ru-6a $\mathbf{a}^{[13]}$ in presence of bleaching earths as additives to prevent the catalyst deactivation.

We initiated our study by evaluating in self-metathesis a refined oil containing $94 \%{ }^{[14]}$ of methyl oleate $(Z)-1$, derived from two successive recrystallizations in acetone (at -37 and $-60{ }^{\circ} \mathrm{C}$, respectively) of the VHOSO raw material (scheme 2). Without any pre-treatment, up to $0.05 \mathrm{~mol} \%$ (500 ppm) of Ru-6a was needed to convert $89 \%$ of (Z)-1 within $15 \mathrm{~min}$ at $50{ }^{\circ} \mathrm{C}$ under neat condition and to reach the equilibrium (Eq. b), affording 2 and 3 in 20 and $22 \mathrm{wt} \%$, respectively. ${ }^{[15]} \mathrm{A}$ significant amount of methyl elaidate $(E)-1$ was also formed (41 wt\%, see ESI for details). It is also important to note that below a catalyst loading of $400 \mathrm{ppm}$, no reactivity was observed. This result clearly demonstrated that, despite the robustness and high stability of the M71 pre-catalyst, ${ }^{[13]}$ the presence of certain substrate impurities has a dramatic effect on catalyst efficiency. Therefore, with the objective to reach an optimal catalytic process, it appeared important to us to clearly identify these poisons and to adapt accordingly. A large variety of organic molecules can be found in vegetal oils (Figure 2).

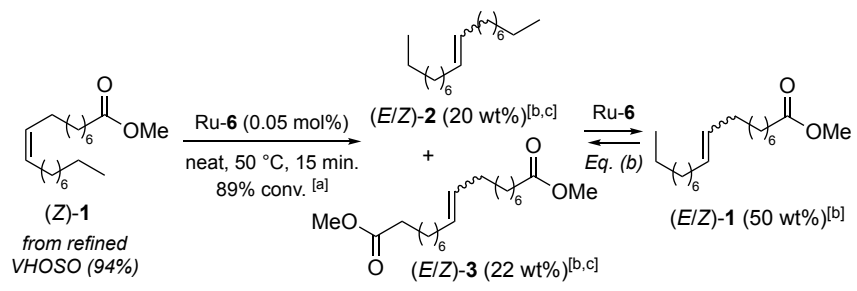

Scheme 2. Self-metathesis of MO (Z)-1 derived from refined VHOSO (94\% of purity) catalyzed by SIPr-M71 Ru-6a. [a] Conversion of (Z)-1, monitored by GC (see ESI for details). [b] Percentage per weight of the composition of the crude at the equilibrium, determined by GC (see ESI). [c] $E / Z$ ratio $=4 / 1$.
Some are naturally present (Np1-3), some are formed during the hydrolysis (Hp1-2) or during the esterification process (Ep1-3) to produce fatty acid/esters, and some are resulting from decomposition by oxidation and/or polymerization (Dp1-3). Because, each of them can act as a potential poison towards either the ruthenium pre-catalyst or the catalytic active species, we decided to investigate their influence onto the rate of the SM reaction (figure 3 and $\mathrm{SI}$ ).

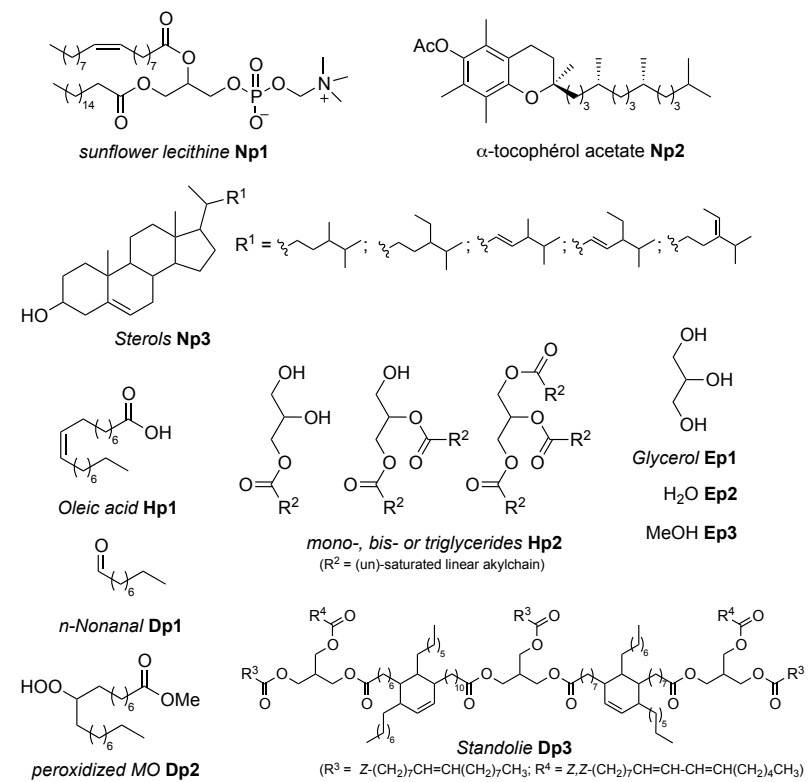

Figure 2. Benchmark of molecules frequently present in fatty esters ( $\mathbf{N p}$ natural products; Hp: hydrolysed products; Ep: products from esterification: Dp: decomposed product)

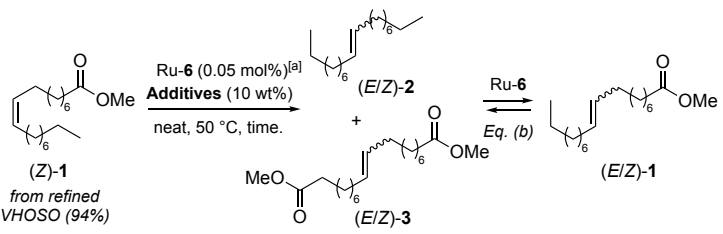

(a)

(b)

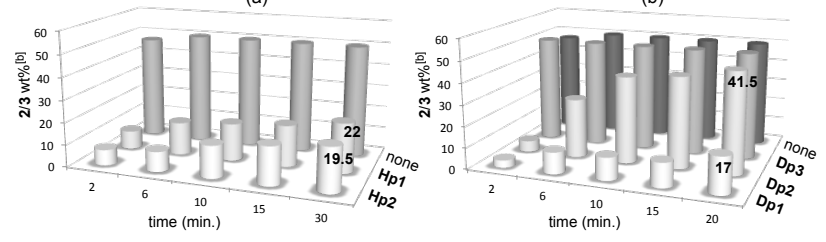

Figure 3. Kinetic profiles of the SM of $M O(Z)-1$ catalyzed by Ru-6a in presence of additives $\mathrm{Hp} \mathrm{(a)} \mathrm{and} \mathrm{Dp} \mathrm{(b).} \mathrm{[a]} \mathrm{Conditions:} \mathrm{Ru-6a}(0.05 \mathrm{~mol} \%)$, additive $(10 \mathrm{wt} \%), 50{ }^{\circ} \mathrm{C}$, neat. [b] Percentage per weight of $2 / 3$ in the crude, determined by GC (see ESI).

While the voluntary contamination with $10 \mathrm{wt} \%$ of lecithine (Np1), $\alpha$-tocopherol acetate (Np2), sterols Np3 or Ep1-3 (i.e. Glycerol, water and methanol) had no effect on the rate of the metathesis reaction (see ESI for details), a noticeable effect was observed after the addition of by-products resulting from the hydrolysis of 
triglycerides (Figure 3-a). In fact, both oleic acid Hp1 and a mix of glycerides $\mathrm{Hp2}$ have significantly slowed down the reaction rate, reaching respectively a maximum of 20 and $22 \mathrm{wt} \%$ of PMP 2/3 after $30 \mathrm{~min}$. A similar behavior was observed with products originating from the fatty esters oxidation (Figure $3-b$ ). Peroxidized methyl oleate Dp2 allowed to reach the equilibrium in $20 \mathrm{~min}$. and only $17 \mathrm{wt} \%$ of PMP were obtained in the presence of $n$-nonanal Dp1. Lastly, no detrimental effect occurred with standolie Dp3 as additive.

The bleaching operation is part of the refining process of crude oils to achieve high quality oil standards for edible applications. The properties of bleaching earths allow for the removal of numerous impurities including oxidation products, resulting in lower peroxide and anisidine values. Extracted from quarries, these natural earths with high adsorption capacity are abundant, cheap and commercially available ${ }^{[16]}$ which make them particularly suited to an industrial application of the Ru-catalyzed SM of methyl oleate. The expected beneficial effect of bleaching earth was confirmed after filtration of the refined oil $(94 \%$ of methyl oleate) on Tonsil Supreme 110FF $\AA^{[16 b]}(100 \mathrm{wt} \%)$, as the equilibrium could be reached with $0.01 \mathrm{~mol} \%$ of Ru-6a (Table 1, entry 1). Nevertheless, $5 \%$ of methyl oleate was lost during the filtration process and we therefore considered performing the metathesis reaction in presence of the bleaching earth.

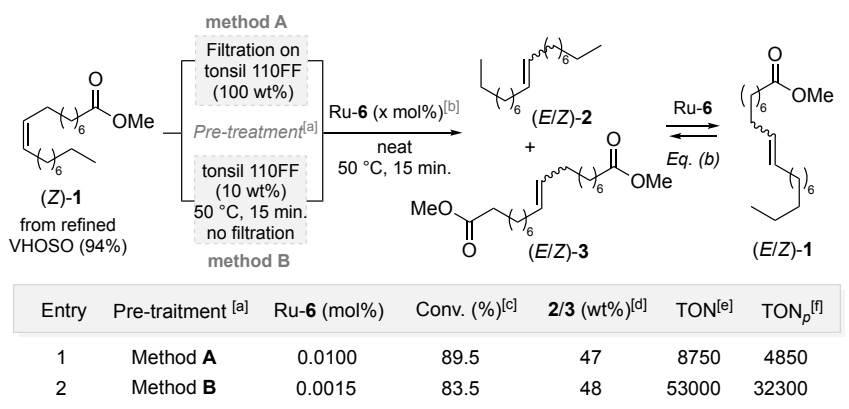

Table 1. Chemical pre-treatments of refined $M O(Z)-1$ with bleaching earths prior SM catalyzed by Ru-6a. [a] Method A: Filtration of (Z)-1 on Tonsil 110FF (100 wt\%); Method B: (Z)-1, Tonsil 110FF (10 wt\%), $50{ }^{\circ} \mathrm{C}, 15 \mathrm{~min}$. [b] Ru-6a $(x \mathrm{~mol} \%), 50{ }^{\circ} \mathrm{C}$, neat, $15 \mathrm{~min}$. [c] Conversions of (Z)-1, monitored by GC (see ESI for details) [d] Percentage per weight of $2 / 3$ in the crude, determined by GC (see ESI). [e] TON=conv. $\times$ (initial moles of $(Z)-1 /$ moles of catalyst) $/ 100$. [f] productive TON of $2+3=$ (moles of $2+3) /($ moles of catalyst).

Interestingly, the treatment of the oil with $10 \mathrm{wt} \%$ of tonsil $110 \mathrm{FF}$ over $15 \mathrm{~min}$ followed by the introduction of Ru-6a led the metathesis reaction to readily reach the equilibrium even with a catalyst loading as low as $0.0015 \mathrm{~mol} \%$ (15 ppm) and a TON of 53000 (Table 1, entry 2). These improved results, prompted us to apply this methodology to a non-refined VHOSO oil containing $85 \%$ of methyl oleate (Radia $7072 \AA$ ) ${ }^{[17]}$ a ton-scale available raw material suitable for industrial scale-up. ${ }^{[18]}$ Nevertheless, probably due to an important level of peroxide detected in the starting material in comparison with the refined oil (28 vs 3.2 meq $\mathrm{O}_{2} / \mathrm{Kg}$, respectively), ${ }^{[19]}$ up to $0.02 \mathrm{~mol} \%$ of catalyst was necessary to reach the equilibrium of the self-metathesis (Table 2 , entry 1). Fortunately, a simple thermic heating at $185^{\circ} \mathrm{C}$ under vacuum (10 mbar) over 2 hours followed by the treatment with $10 \mathrm{wt} \%$ bleaching earth $\left(50{ }^{\circ} \mathrm{C}, 15 \mathrm{~min}\right.$.) allowed to reach the equilibrium within 1 hour at extremely low $0.0005 \mathrm{~mol} \%$ catalyst loading (5 ppm, entry 3 ). Taking into account its abrasive nature that may damage the stainless-steel reactor at pilot scale, we decided to further diminish the amount of the bleaching earth. The optimal conditions were later found by increasing the time contact between the sorbent and the starting material (up to $120 \mathrm{~min}$ ). With $1 \mathrm{wt} \%$ of the bleaching earth, the equilibrium of metathesis was reached with an extremely low loading of Ru-6a (0.0005 mol\%, entry 6$){ }^{[20]}$ Remarkably, under these conditions, the catalyst remained active at $1 \mathrm{ppm}$ loading, converting $65 \%$ of the non-refined $\mathrm{MO}(Z)-1$ to achieve an impressive TON of 744000 and a related productive TON of 359000 (entry 7). This is the first time a catalytic system has exhibited such high performance in a self-metathesis reaction of methyl oleate. ${ }^{[8]}$

\begin{tabular}{|c|c|c|c|c|c|c|c|c|}
\hline 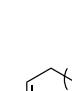 & Pre & $\begin{array}{l}\text { e-treatment } 1 \\
185^{\circ} \mathrm{C} \\
10 \mathrm{mbar}, 2 \mathrm{~h}\end{array}$ & Ru-6 $(x \mathrm{~m}$ & ol\%) & & & $\stackrel{\mathrm{Ru}-6}{\longrightarrow}$ & \\
\hline$\left(Y_{6}\right.$ & & $\begin{array}{c}\text { Tonsil } 110 \mathrm{FF} \\
\text { (wt\%), } 50^{\circ} \mathrm{C} \\
15 \mathrm{~min} .\end{array}$ & neat, $50^{\circ} \mathrm{C}$ & time & & & Eq. ( & \\
\hline $\begin{array}{l}\text { rom non } \\
\text { VHOSC }\end{array}$ & $\begin{array}{l}\text {-refined Pre } \\
(85 \%)\end{array}$ & e-treatment 2 & & & & & & $(E / Z)-1$ \\
\hline Entry & $\begin{array}{l}\text { Pre- } \\
\text { traitment } 1^{[a]}\end{array}$ & $\begin{array}{c}\text { Tonsil 110FF } \\
(w t \%)^{[b]}\end{array}$ & $\begin{array}{c}\text { Ru-6 } \\
(\mathrm{mol} \%)^{[\mathrm{c}]}\end{array}$ & $\begin{array}{l}\text { time } \\
\text { (min.) }\end{array}$ & $\begin{array}{l}\text { Conv. } \\
(\%)^{[d]}\end{array}$ & $\begin{array}{c}2 / 3 \\
(w t \%)^{[e]}\end{array}$ & TON $\left[\mathrm{N}^{[f]}\right.$ & $\mathrm{TON}_{p}{ }^{[g]}$ \\
\hline 1 & none & none & 0.06 & 15 & 90 & 43 & 1570 & 850 \\
\hline 2 & none & 10 & 0.02 & 15 & 97 & 43 & 5060 & 2700 \\
\hline 3 & with & 10 & 0.0005 & 60 & 88 & 43 & 202100 & 115400 \\
\hline 4 & with & 3 & 0.001 & 60 & 89 & 43 & 102100 & 57400 \\
\hline 5 & with & 1 & 0.002 & 60 & 90 & 43 & 51600 & 28500 \\
\hline 6 & with & 1 (120 min.) & 0.0005 & 60 & 90 & 43 & 172500 & 94700 \\
\hline 7 & with & 1 (120 min.) & 0.0001 & 60 & 65 & 27 & 744000 & 359000 \\
\hline
\end{tabular}

Table 2. Optimization of bleaching earth pre-treatments towards non-refined MO (Z)-1 prior SM catalyzed by Ru-6a. [a] $185^{\circ} \mathrm{C}, 10$ mbar, 2 h. [b] Tonsil $110 \mathrm{FF}$ (y wt\%), $50{ }^{\circ} \mathrm{C}, 15 \mathrm{~min}$. [c] Ru-6a (x mol\%), $50{ }^{\circ} \mathrm{C}$, neat. [d] Conversions of (Z)-1, monitored by GC (see ESI for details). [e] Percentage per weight of $2 / 3$ in the crude, determined by GC (see ESI). [f] TON=conv. $\times($ initial moles of $(Z)-1 /$ moles of catalyst $) / 100$. [g] productive TON of $2+3=($ moles of $2+3) /($ moles of catalyst $)$.

Intrigued by this remarkable efficiency to trap poisons from the crude oil without any noticeable detrimental side effects on the catalytic activity, we decided to investigate the interaction between the bleaching earth and the ruthenium catalyst. Surprisingly, when Ru-6a (0.002 mol\%) was pre-mixed with tonsil 110FF (1 wt\%), no metathesis transformation of $\mathrm{MO}$ occurred (Scheme 3, a). A similar inactivity was also observed at higher catalyst loading $(0.1 \mathrm{~mol} \%)$. Moreover, the total lack of activity was confirmed in an attempt to perform the ring-closing metathesis (RCM) of 1,7-octadiene 4 (Scheme 3, b). As Tonsil $110 \mathrm{FF}$ is mainly composed by silica $(75.5 \%),{ }^{[21]}$ we suspected a rapid impregnation of the ruthenium catalyst, as depicted in scheme 3. Indeed, after dissolving Ru-6a in dichloromethane (picture A), the green color fully disappeared after the addition of the bleaching earth (10 wt $\%$, picture B). The resulting colorless supernatant was then used in SM of (Z)-1 or RCM of $\mathbf{4}$ and showed no metathesis activity, attesting the complete impregnation of the catalyst with the tonsil. Moreover, the 
impregnated catalyst was also inactive. ${ }^{[22]}$ On the other hand, when the tonsil 110FF is mixed with the non-refined oil prior the addition of the catalyst (picture $\mathbf{C}$ ), the resulting supernatant remained green (picture D) and displayed good catalytic activity in metathesis of 4 (>99\% within 5 min, see ESI for details). All these experiments showed that the bleaching earth is able to rapidly deactivate the ruthenium complex ${ }^{[23]}$ but becomes totally inert toward the catalyst after the adsorption of impurities contained in a non-ultra-pure oil.

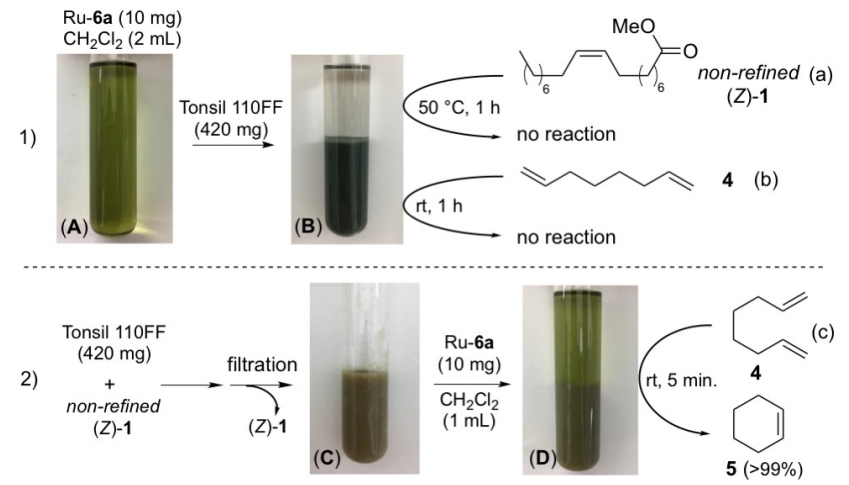

Scheme 3. Deactivation of the Ru-6a catalyst by impregnation onto Tonsil $110 \mathrm{FF}$ bleaching earth.

We continued our optimization study by screening alternative commercially available sorbents (Figure 4). Introduced at $1 \mathrm{wt} \%$, most of the sorbents allowed for modest catalytic activity with 20 ppm of Ru-6a. For instance, under our conditions, the use of magnesium silicate (magnesol ${ }^{\circledR}$ D60) which has been widely employed in oil pre-treatment ${ }^{[12 \mathrm{~d}]}$ led to a low production of 14 wt\% PMP 2/3. Durcal 2, Trisyl or Flucat 22B showed better efficiency, but with up to $29 \mathrm{wt} \%$ of $2 / 3$ in the best case. The optimal production of PMP $2 / 3$ was obtained with bleaching earths Tonsil $110 \mathrm{FF}$ and $112 \mathrm{FF}$ as well as the less costattractive silica hydrogel trisyl 300 . Therefore, we chose to pursue our study with the cheap Tonsil 110FF.

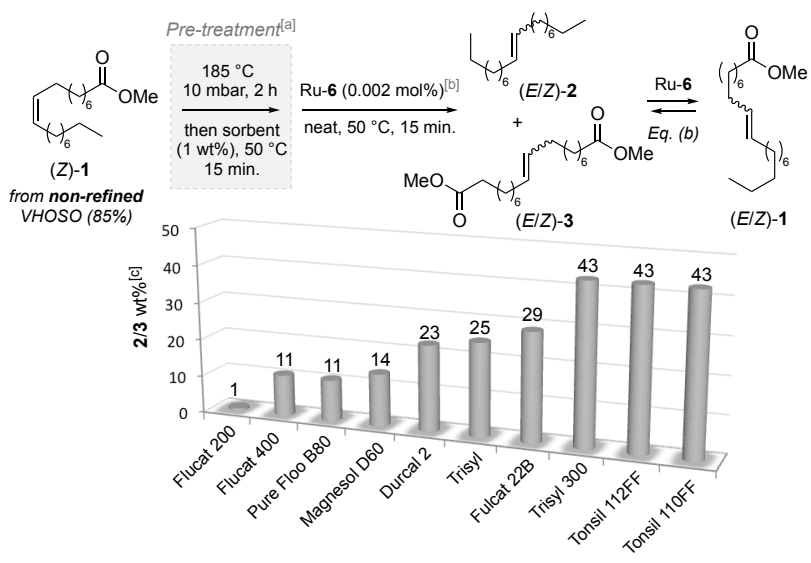

Figure 4. Screening of sorbents for the pretreatment of non-refined $\mathrm{MO}(Z)-1$ prior SM catalyzed by Ru-6a. [a] Condition: $185^{\circ} \mathrm{C}, 10 \mathrm{mbar}, 2 \mathrm{~h}$ then sorbent (1 wt $\%), 50{ }^{\circ} \mathrm{C}, 15 \mathrm{~min}$. [b] Condition: Ru-6a $(0.002 \mathrm{~mol} \%), 50^{\circ} \mathrm{C}$, neat, $1 \mathrm{~h}$. [c] Percentage per weight of $2 / 3$ in the crude, determined by GC (see ESI).
With this cost-effective and efficient pretreatment condition in hands, the SM of non-refined MO (Z)-1 was re-investigated with alternative commercially available complexes Ru-2,3 and Ru-5,6 (Figure 5). Under our condition, first generation catalysts bearing $\mathrm{PCy}_{3}$ ligands $(\mathrm{Ru}-2 \mathrm{a}, 3 \mathbf{3})$ were totally inactive. While second generation complexes bearing the SIMes ligand (Ru$\mathbf{2 b}, \mathbf{3 b}$ ) displayed poor activities to produce 13 to $15 \mathrm{wt} \%$ of PMP 2/3, no reactivity was observed with Evonik catalyst Ru-3c bearing the unsaturated IMes ligand. On the other hand, phosphine-free complexes Ru-5,6 appeared more robust demonstrating relatively similar levels of efficiency ( 40 to $43 \mathrm{wt} \%$ of PMP 2/3).

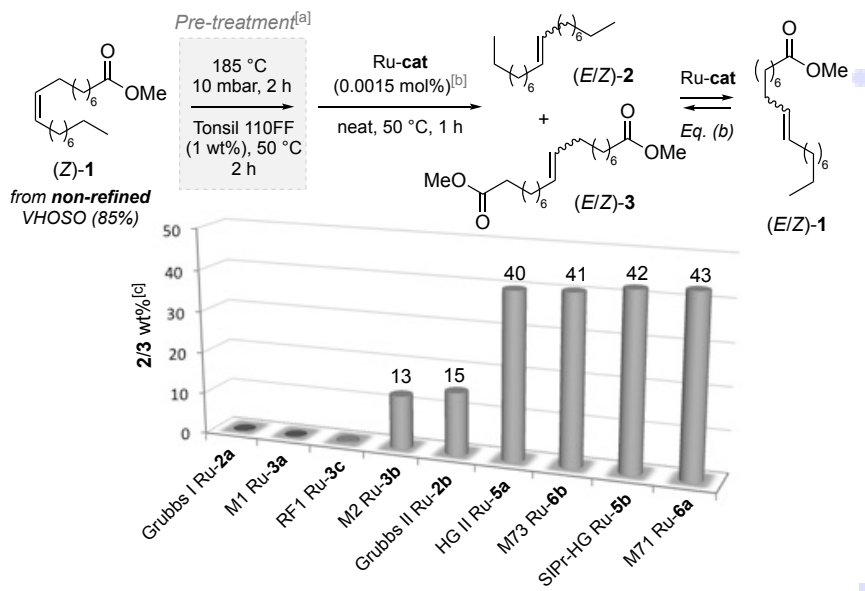

Figure 5. Screening of commercially available catalysts Ru-2-3 and Ru-5-6 in the SM of non-refined $\mathrm{MO}(Z)-1$. [a] Conditions: $185^{\circ} \mathrm{C}, 10 \mathrm{mbar}, 2 \mathrm{~h}$ then sorbent $(1 \mathrm{wt} \%), 50{ }^{\circ} \mathrm{C}, 2 \mathrm{~h}$. [b] Conditions: Ru-catalyst $(0.0015 \mathrm{~mol} \%), 50{ }^{\circ} \mathrm{C}$, neat, $1 \mathrm{~h}$. [c] Percentage per weight of $2 / 3$ in the crude, determined by GC (see ESI).

SIPr-M71 Ru-6a, which afforded the highest conversion, was selected for the scale-up development of the transformation (Table 3). The first attempt at $1 \mathrm{Kg}$ scale was performed using $0.01 \mathrm{~mol} \%$ of Ru-6a. After the thermic treatment, the non-refined $\mathrm{MO}$ was reacted with $1 \% \mathrm{wt}$ of Tonsil $110 \mathrm{FF}$ at $50^{\circ} \mathrm{C}$. The media turned rapidly brown with a slight exothermic reaction $\left(10^{\circ} \mathrm{C}\right)$. After the addition of Ru-6a, the equilibrium was reached within 15 min with $83.5 \%$ conversion, affording PMP 2 and 3 in 39 wt\% (entry 1). We next attempted the metathesis at $3 \mathrm{Kg}$ scale with $0.0005 \mathrm{~mol} \%$ of catalyst (5 ppm). The excellent conversion with a high TON of 189000 observed after $1 \mathrm{~h}$ attested for the robustness of the pretreatment and prompted us to perform a pilot-scale production $(200 \mathrm{~kg})$. In a $300 \mathrm{~L}$ reactor, the addition of Tonsil 110FF, preceded by a thermic pretreatment that decreased the peroxide content from 18 to $0.09 \mathrm{meq} \mathrm{O}_{2} / \mathrm{Kg}$, allowed for an excellent olefin metathesis performance, as the equilibrium was reached within $15 \mathrm{~min}$ converting the nonrefined $M O(Z)-1$ in $88 \%$ (entry 3 , see the kinetic profile in $\mathrm{ESI}){ }^{[24]}$ Importantly, no evolution of the equilibrium was observed over $5 \mathrm{~h}$ leading to PMP 2 and 3 in $41 \mathrm{wt} \%$. Therefore, a remarkable TON of 174000 was reached at the equilibrium, with a productive TON of 94900 . 


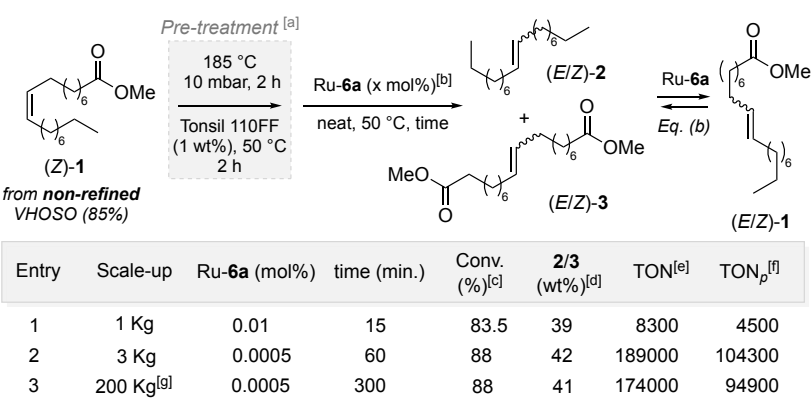

Table 3. Scale-up development of SM of non-refined $\mathrm{MO}(Z)-1$ catalyzed by Ru-6a. [a] Conditions: $185^{\circ} \mathrm{C}, 10 \mathrm{mbar}, 2 \mathrm{~h}$ then sorbent $(1 \mathrm{wt} \%), 50{ }^{\circ} \mathrm{C}, 2 \mathrm{~h}$ [b] Ru-6 (x mol\%), $50{ }^{\circ} \mathrm{C}$, neat. [c] Conversions of (Z)-1, monitored by GC (see ESI for details). [d] Percentage per weight of $2 / 3$ in the crude, determined by GC (see ESI). [e] TON=conv. $\times$ (initial moles of $(Z)-1 /$ moles of catalyst) $/ 100$. [f] productive TON of $\mathbf{2}+\mathbf{3}=$ (moles of $\mathbf{2}+\mathbf{3}) /($ moles of catalyst). [g] Tonsil $110 \mathrm{FF}$ reacted with MO over 2 h 30 .

In conclusion, an efficient, practical and cost-effective pretreatment through the use of cheap bleaching earths was proposed to mediate the ruthenium-catalyzed self-metathesis of non-refined methyl oleate (Z)-1 (85\% of purity) derived from Very High Oleic Sunflower Oils at very low catalyst loading. The use of commercially available bleaching earth Tonsil 110FF ${ }^{(1}$ wt\%) combined with a thermic pretreatment enabled to trap all poisons presents in the raw material without any requirement of filtration prior the metathesis. With a catalytic loading of 0.0005 $\mathrm{mol} \%$ (5 ppm) of SIPr-M71 pre-catalyst, non-refined (Z)-1 was converted in up to $90 \%$ within 1 hour at $50{ }^{\circ} \mathrm{C}$ under neat conditions and the expected primary metathesis products, the 9octadecene $\mathbf{2}$ and the dimethyl-9-octadecenoate $\mathbf{3}$, were produced in $43 \mathrm{wt} \%$. Importantly, the catalytic system remained active as low as $1 \mathrm{ppm}$ enabling reaching $65 \%$ conversion with the highest TON of 744000 . The robustness of the catalytic process has proven to be also efficient at pilot-scale (up to 200 $\mathrm{Kg}$ ) with an impressive productive TON of 94900. Application of this efficient and scalable pre-treatment protocol is currently investigated to other valuable and challenging metathesis transformations of non-refined vegetable oils, such as alkenolysis of fatty ester/acids. ${ }^{[2]}$

\section{Acknowledgements}

This work was supported by the Agence Nationale de la Recherche (ANR-12-CD2I-0002 CFLOW-OM). MM thanks Rennes Métropole and the Région-Bretagne (SAD $\left.n^{\circ} 8734\right)$ for their financial supports concerning the development of Ru-based complexes. We are grateful to the ANRT and Oléon (Grant to I.C. and J.A., CIFRE $n^{\circ}$ 2012/0182), the CNRS and the ENSCR.

Keywords: Olefin Metathesis • ruthenium• oleochemicals • bleaching earths $\cdot$ pilot production

[1] Report of the United Nations Conference on Environmental Development, Rio de Janeiro (Brazil) http://www.un.org/esa/sustdev, Accessed 1992
[2] 179 millions tons per year have been produced in 2015/2016, see: J Spekreijse, J. P. M. Sanders, J. H. Bitter, E. L. Scott, ChemSusChem 2017, 10, 470 and references cited therein.

[3] Selected comprehensive books on olefin metathesis: (a) R. H. Grubbs, A. G. Wenzel, D. J. O'Leary, E. Khosravi, (Eds.) Handbook of Metathesis, $2^{\text {nd }}$ Edition; Wiley-VCH: Weinheim, Germany, 2015; (b) K. Grela (Ed.), Olefin Metathesis: Theory and Pratice, Wiley-VCH: Weinheim, Germany, 2014.

[4] For a review, see: A. Rybak, P. A. Fokou, M. A. R. Meier, Eur. J. Lip. Sci. Technol. 2008, 110, 797.

[5] (a) Y.-M. Choo, K.-E. Ooi, I.-H. Ooi, D. D. H. Tan, J Am Oil Chem Soc. 1996, 73, 333; (b) W. Keim, Angew. Chem. Int. Ed. 2013, 52, 12492.

[6] M. A. R. Meir, J. O. Metzger, U. S. Schubert, Chem. Soc. Rev., 2007 36, 1788. See also ref. 4.

[7] M. B. Dinger, J. C. Mol, Adv. Synth. Catal. 2002, 344, 671.

[8] R. Kadyrov, C. Azap, S. Weidlich, D. Wolf, Top. Catal. 2012, 55, 538.

[9] See for instance: M. Rouen, P. Queval, E. Borré, L. Falivene, A. Poater, M. Berthod, F. Hugues, L. Cavallo, O. Baslé, H. Olivier-Bourbigou, M. Mauduit, ACS Catal. 2016, 6, 7970.

[10] Extra-pure methyl oleate (>99\%) is commercialized by Aldrich $(62 € / 5 \mathrm{~g})$.

[11] S. Chikkali, S. Mecking, Angew. Chem. Int. Ed. 2012, 51, 5802.

[12] (a) D. W. Lemke, K. D. Uptain, F. Amore, T. Abraham, PCT Int. Appl. WO 2009/020667; (b) Z. Lysenko, B. R. Maughon, J. Bicerano, K. A. Burdett, C. P. Christenson, C. H. Cummins, M. L. Dettloff, J. M. Maher, A. K. Schrock, P. J. Thomas, R. D. Varjian, J. E. White, PCT Int. Appl. WO 2003/093215; (c) S. A. Cohen, D. R. Anderson, Z. Wang, T. M. Champagne, T. A. Ung, US Pat. 2014/0275681; (d) K. D. Uptain, C. Tanger, H. Kaido, PCT Int. Appl. WO 2009/020665.

[13] M71-SIPr is commercialized by Umicore company (www.umicore.com). For the related publication, see: H. Clavier, F. Caijo, E. Borré, D. Rix, F. Boeda, S. P. Nolan, M. Mauduit, Eur. J. Org. Chem. 2009, 25, 4254.

[14] The other compounds were identified as saturated and mono- or polyunsaturated fatty methyl esters: C14:0 (0.02 wt.\%); C14:1 (0.01 wt.\%); C16:0 (2.7 wt.\%); C16:1 (0.03 wt.\%); C18:0 (1.3 wt.\%); C18:2 (1.6 wt. \%); C22:0 (0.06 wt.\%) and C22:1 (0.2 wt.\%).

[15] The kinetic profile of the reaction showed that the equilibrium was reached within 4 min (See ESI for details).

[16] (a) For more information, see: Oils\&Fats International, june 2016, 32(5), pp 26-31; (b) Tonsil囚 bleaching earths are commercialized by Clariant.

[17] Radia $7072 \AA$ is commercialized by Oleon company. The other compounds were identified as saturated and mono- or poly-unsaturated fatty methyl esters: C16:0 (3.4 wt.\%); C16:1 (0.1 wt.\%); C18:0 (1.8 wt.\%); C18:2 (3.1 wt.\%); C18:3 (1.8 wt.\%); C20:0 (0.2 wt.\%) C22:0 (0.3 wt.\%) and C22:1 (0.7 wt.\%).

[18] The recrystallization process leading to a better quality of raw material (i.e. $94 \%$ ) appeared too costly and inappropriate at industrial scale.

[19] The peroxide value is defined as the amount of peroxide oxygen per 1 kilogram of oil and is determined by measuring the amount of iodine which is formed by the reaction of peroxides with iodide ion.

[20] Composition of the crude after filtration: (Z/E)-2 (15.7 wt.\%), (Z/E)-3 (27.2 wt.\%), (E)-1 (26.6 wt.\%), (Z)-1 (8.2 wt.\%).

[21] Composition of Tonsil Supreme 110FF® (average values): $\mathrm{SiO}_{2}$ (75.5\%), $\mathrm{Al}_{2} \mathrm{O}_{3}$ (12\%), $\mathrm{Fe}_{2} \mathrm{O}_{3}(2.4 \%), \mathrm{CaO}(0.4 \%), \mathrm{MgO}(1.4 \%), \mathrm{Na}_{2} \mathrm{O}$ $(0.3 \%), \mathrm{K}_{2} \mathrm{O}(1 \%)$.

[22] SIPr-M71 impregnated onto amorphous silica has proved to be quite efficient in olefin metathesis, see: H. Nasrallah, D. Dragoe, C. Magnier, C. Crévisy, M. Mauduit, E. Schulz, ChemCatChem 2015, 7, 2494.

[23] (a) Additional experiments were done showing the detrimental effect of a mixture of metallic oxides $\left(\mathrm{Fe}_{2} \mathrm{O}_{3}, \mathrm{CaO}\right.$ and $\left.\mathrm{MgO}\right)$ towards the $\mathrm{Ru}$ catalyst (see ESI for details). For previous studies reporting the catalyst decomposition by oxidation, see: (b) D. W. Knight, I. R. Morgan, A. J. Proctor, Tetrahedron Lett. 2010, 51, 638. (c) M. Mauduit, F. Caijo, C. Crévisy, PCT Int. Appl. WO 2009/0805403; (d) A. Jana, K. Grela, Org. Lett. 2017, 19, 520 .

[24] Composition of the crude after filtration: (Z/E)-2 (15.8 wt.\%); (Z/E)-3 (25.4 wt.\%); (E)-1 (38.5 wt.\%); (Z)-1 (10.2 wt.\%). 


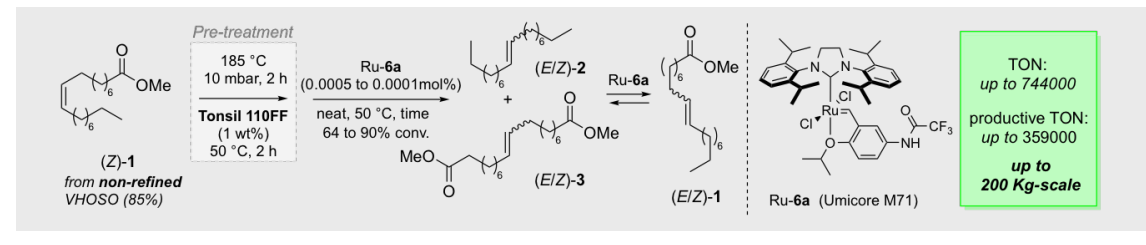

An efficient and cost-effective pretreatment was proposed to mediate the Rucatalyzed self-metathesis of non-refined methyl oleate (Z)-1 (85\%) derived from Very High Oleic Sunflower Oils (VHOSO). The use of bleaching earths (Tonsil $110 \mathrm{FF}, 1 \mathrm{wt} \%)$ combined with a thermic pretreatment enabled metathesis under neat conditions with a catalytic loading as low as $0.0001 \mathrm{~mol} \%$ (1 ppm) and impressive turnover number (TON) of 744000 . The robust catalytic process has proven to be efficient at pilot scale $(200 \mathrm{Kg})$ with a remarkable productive TON (94900) for expected primary metathesis products 9-octadecene 2 and dimethyl-9octadecenoate 3 .
Jessica Allard, ${ }^{[a, b]}$ Idriss Curbet, ${ }^{[a]}$ Guillaume Chollet, ${ }^{[c]}$ Fabien Tripoteau, ${ }^{[d]}$ Sophie Sambou, ${ }^{[b]}$ Frédéric Caijo, ${ }^{[d]}$ Yann Raoul, ${ }^{[b]}$ Christophe Crévisy, ${ }^{[a]}$ Olivier Baslée ${ }^{[a]}$ and Marc Mauduit ${ }^{[a] *}$

Bleaching Earths as Powerful Additives for Ru-Catalyzed SelfMetathesis of Non-Refined Methyl Oleate at Pilot Scale. 